Elizabeth E. Crone

\title{
Desynchronization and re-synchronization of reproduction by Astragalus scaphoides, a plant that flowers in alternate years
}

Received: 22 November 2010/ Accepted: 12 March 2012/Published online: 11 April 2012

(C) The Ecological Society of Japan 2012

\begin{abstract}
Mast seeding, the synchronous seed production by plants at irregular intervals, has been widely studied from the perspective of its fitness benefits, but much less is known about the proximate factors that cause plants to reproduce synchronously. In this article, I follow up on more than two decades of research investigating proximate mechanisms of mast seeding by Astragalus scaphoides, an iteroparous perennial forb. We use longterm monitoring in relation to two environmental manipulations to evaluate the importance of exogenous environmental factors versus endogenous feedbacks for synchrony in this species. Our past research showed that synchrony in this species is explained by the pollencoupling hypothesis: plants that flower synchronously set seed and deplete stored resources, whereas plants that happen to flower asynchronously are pollen limited, set fewer seeds, and do not deplete resources, and flower again until they are resynchronized. Continued monitoring of two experimental manipulations, water addition, and flower removal, provides additional support for this model, and also reveals subtle effects of water availability on synchrony. Water addition decreased flowering, rather than increasing it as expected based on simple correlations with weather variables, suggesting that precipitation does not synchronize reproduction. Exogenous drivers are generally considered to be the primary synchronizing factors in plant reproduction. Our work in this system suggests that endogenous feedbacks may be more important than has been previously assumed.
\end{abstract}

Keywords Mast seeding - Costs of reproduction · Water limitation · Pollen limitation - Chaos · Synchrony $\cdot$ Astragalus scaphoides $\cdot$ El Niño $\cdot$ Pollen coupling $\cdot$ Resource budget

\section{E. E. Crone $(\bowtie)$}

Harvard Forest, Harvard University, 324 N. Main Street,

Petersham, MA 01366, USA

E-mail: ecrone@fas.harvard.edu

\section{Introduction}

Population-level fluctuations of seed output, known as mast seeding or masting, are a relatively common phenomenon in plants. Masting has the potential to have far-reaching effects on community and ecosystem dynamics (Janzen 1976; Ostfeld and Keesing 2000; Kelly and Sork 2002). A large body of literature has addressed the reasons why masting occurs from an evolutionary perspective, in other words, fitness advantages of synchronous reproduction (reviewed by Kelly and Sork 2002). Fewer studies have looked at how masting occurs from a proximate ecological perspective. In general, we do not know how trees are able to synchronize reproduction at super-annual time scales. Nonetheless, understanding how synchrony arises is central to predicting how changes in the environment would affect patterns of seed production by plants, and subsequent dynamics of seed consumers and plant communities.

Investigations of proximate mechanisms of synchronous mast seeding have drawn on two categories of explanations, which are not mutually exclusive. The first category explains mast seeding based on exogenous environmental factors, i.e., synchronous environmental forcing of individual reproduction through fluctuations in resource availability (Norton and Kelly 1988; McKone et al. 1998; Schauber et al. 2002; Abrahamson and Layne 2003; Kelly et al. 2008), or cues for flower induction (Ashton et al. 1988; Piovesan and Adams 2001), also known as a Moran effect (Liebhold et al. 2004a). The second category invokes endogenous mechanisms of synchrony, i.e., feedbacks within or among individuals that lead to synchronous dynamics through time, also known as phase locking (Liebhold et al. 2004a). Isagi et al. (1997) and Satake and Iwasa $(2000,2002)$ formalized this mechanism in the context of mast seeding. These "resource-budget" and "pollencoupling" models assume that an individual plant requires more resources to flower and set seed than it gains in a year, and therefore flowers only above some 
threshold amount of stored resources. These rules can cause plants to have cyclical or chaotic patterns of reproduction over time (Isagi et al. 1997). In the presence of cyclical reproduction by individuals, only small amounts of environmental variation (e.g., frost events that kill buds) are needed to synchronize individuals within plant populations (Satake and Iwasa 2002). In addition, if plants are pollen-limited in low-flowering years, synchronous mast seeding could occur even in the absence of any environmental variation (Satake and Iwasa 2000). Exogenous mechanisms remain the most common explanation for synchronous mast seeding (Koenig and Knops 1998; Schauber et al. 2002; Kelly and Sork 2002; Kelly et al. 2008). However, three modeling studies have shown that endogenous resource dynamics are necessary to explain synchrony, whereas exogenous factors alone cannot (Rees et al. 2002; Crone et al. 2005; Lyles et al. 2009).

For the past two decades, my colleagues and I have studied causes of synchronous reproduction by Astragalus scaphoides, a perennial herb that flowers in alternate years (Lesica 1995; Crone and Lesica 2004). Initially, we believed that reproduction might be synchronized by exogenous factors, particularly precipitation during bud initiation, in this semi-arid environment. However, we found at best weak effects of environmental drivers on flowering dynamics (Crone and Lesica 2004, 2006; Crone et al. 2005). Instead, our research has shown that flowering is synchronized largely by endogenous processes, not by external cues such as fluctuations in resource availability. When individual plants flower synchronously with other plants in the population, seed set depletes stored nonstructural carbohydrates (NSC) which prevents flowering the following year (Crone et al. 2009). When plants flower asynchronously, they are pollen-limited, and set fewer seeds (Crone and Lesica 2006), which prevents NSC depletion (Crone et al. 2009). Therefore, these individual plants should flower in subsequent years until they become synchronized with others in the population. These mechanisms largely conform to the pollen-coupling model, and variants of these models fit to our data show that endogenous processes are both necessary and sufficient to explain synchronous flowering in this species (Crone et al. 2005).

In this paper, I follow up on three of our past analyses to evaluate whether flowering dynamics after our initial publications have continued to support the importance of endogenous processes in synchronizing reproduction in this species. I also use these follow-up studies to test whether longer-term monitoring revealed stronger signals of exogenous environmental drivers. The first of these studies is an analysis of monitoring at three sites (Crone and Lesica 2004; Crone et al. 2005), in which we previously analyzed patterns from 1986 to 1999 , and for which monitoring is ongoing. The second is an experiment in which we attempted to desynchronize plants in these plots by adding supplemental water from 2000 to 2002 (Crone and Lesica 2006). The third is an experiment in which we attempted to desynchronize plants by preventing seed set in 2005, a high-flowering year (Crone et al. 2009). Experimental studies of synchrony in natural populations are rare in general (cf. Bjørnstad 2000); therefore, these studies are unusual in that they have tested causes of mast seeding directly, using manipulative experiments to shift patterns of reproduction over multiple years.

For each of these studies I, first, review the study design and published results, then describe the analyses I used to follow up on these studies, and the results of these analyses. After explaining each study, in turn, I discuss general implications of these long-term dynamics for understanding mechanisms of synchrony in this and other species.

\section{Study system}

Astragalus scaphoides (Fabaceae) is an iteroparous perennial legume, endemic to high-elevation sagebrush steppe in a small area of Beaverhead County in southwestern Montana (MT) and adjacent Lemhi County in east-central Idaho (ID) (Barneby 1964). Local populations are scattered on south-facing slopes with relatively deep soils. Summers are dry; mean annual precipitation in Lemhi and Beaverhead counties is $\sim 250 \mathrm{~mm}$, with peak rainfall in May. Flowering occurs from late May to mid-June. In most years, plants dehisce seeds by midJuly. A. scaphoides was formerly a candidate for listing by the US Fish and Wildlife Service as a threatened or endangered species, but demographic monitoring suggested that populations were stable or increasing (Lesica 1995; see Fig. 1), and the species was removed from consideration for listing.

Astragalus scaphoides is an herbaceous plant that produces one to many $15-40 \mathrm{~cm}$ inflorescences, and has long, narrow, woody roots (Lesica 1995). A. scaphoides does not reproduce vegetatively, and, like many Astragalus species (Karron 1987; Geer et al. 1995), is visited by a number of generalist bumblebees (Bombus spp.) and solitary bees (including Anthophora spp., and Osmia spp.; Crone, unpublished data). Bees trip flowers, and release pollen. Most A. scaphoides populations occur on lands subject to cattle grazing. Inflorescences are eaten by cattle and deer, and cut off by ants, which leave the inflorescences on the ground next to the plants. Ripening seed pods are often attacked by weevils and ant-tended lycaenid caterpillars (Crone and Lesica, unpublished data). A. scaphoides has an estimated lifespan of 21 years, conditional on reaching reproductive stage (Ehrlèn and Lehtilä 2002), noticeably shorter than mast seeding trees. We cannot yet calculate lifespans empirical because our 25-year demographic study is not yet long enough; at Sheep Corral Gulch, the site with our longest and most complete data, only 83 of 325 flowering plants were born after 1986 and died by 2010 .

In 1986, two permanent monitoring transects were established at each of two sites (Sheep Corral Gulch, Montana, and Haynes Creek, Idaho, USA; Lesica 1995). 
In 1988, transects were added at a third site in Idaho (McDevitt Creek), and in 2003, we added a fourth site in Montana (Reservoir Creek). The Montana sites are $\sim 60 \mathrm{~km}$ from the Idaho sites; the two sites in each state are separated by $\sim 20 \mathrm{~km}$. Weather records from the nearby cities of Dillon, MT, and Salmon, ID, suggest that the Idaho sites are warmer and wetter (mean annual temperature is $7.9{ }^{\circ} \mathrm{C} ; 255 \mathrm{~mm}$ average annual precipitation) than the Montana sites (mean annual temperature is $7.08{ }^{\circ} \mathrm{C} ; 243 \mathrm{~mm}$ average). Each transect consisted of 50 adjacent $1-\mathrm{m}^{2}$ mapping quadrats placed along a transect line. In early July, when most fruits were mature and vegetative plants had not yet senesced, the position of each $A$. scaphoides plant encountered in the quadrats was mapped, and total inflorescence production and inflorescence fate (aborted, browsed, number of mature seed pods) were recorded. Each transect was censused in each year through 1999, and again from 2003 through the present. Individual plant trajectories were followed over time by overlaying maps (Lesica 1987).

The water addition experiment (experiment \#1, below) was done in two of the monitoring transects, McDevitt Creek and Sheep Corral Gulch. During this experiment, plants were mapped only in experimental (control, pulse-watered, and press-watered) plots; estimates of the total number of flowering plants in these years were inferred from regressions of flowering in these plots versus the whole population. The flower removal experiment took place near two of the monitoring transects, Sheep Corral Gulch and Reservoir Creek. Manipulations at Reservoir Creek took place adjacent to the monitoring transect. Manipulations near Sheep Corral Gulch took place, on a ridge, $500 \mathrm{~m}$ from the monitoring, so I refer to this site as "Sheep Corral
Ridge" to make it clear these sites were close but not adjacent.

\section{Spatiotemporal patterns of synchrony}

Past research

We (Crone and Lesica 2004) evaluated spatiotemporal patterns of synchrony, and potential drivers of synchrony, using monitoring data collected at Haynes Creek, McDevitt Creek, and Sheep Corral Gulch between 1986 and 1999. Over these 14 years, plants tended to flower in alternate years, as evidenced by negative lag-1 autocorrelations, and a bimodal distribution of the number of flowering plants through time (Crone and Lesica 2004; see Fig. 1). Flowering by individuals was synchronous, both within and among sites, with only a slight tendency toward stronger synchrony within than among sites (Crone and Lesica 2004).

Analyses of these time series revealed two potential drivers of synchrony within sites. First, the number of flowering plants was higher in years with more precipitation during March, which is just prior to emergence in April (Pearson correlation: $r=0.394, n=39$ site $\times$ year observations, $p=0.0132$ ). Second, plants set more seed pods per inflorescence in high-flowering years, suggesting pollen limitation in low-flowering years (logistic regression: slope $=0.028, n=39, \chi^{2}=406.8$, $p<0.001)$. These relationships provided the rationale for our water addition and flower removal experiments, described below.

In addition, we speculated about causes of among-site synchrony. One possibility would be shared environmental
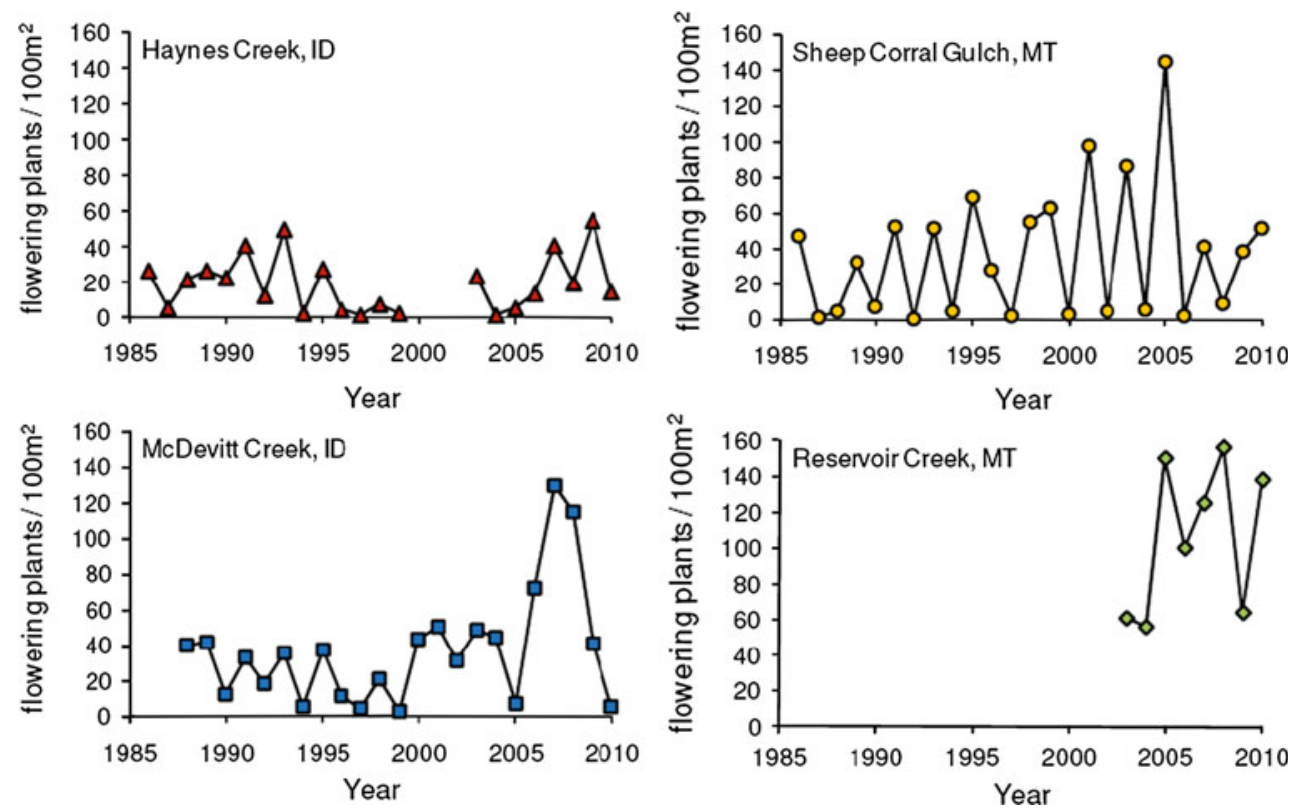

Fig. 1 Flowering dynamics of Astragalus scaphoides at four sites in Montana and Idaho. Counts during the watering experiment (2000-2002, Sheep and McDevitt) were inferred from unmanipulated control plots 
correlations, such as March precipitation (e.g., correlation between weather stations in ID and MT: $r=0.503$, $n=14$ years, $p=0.0799$ ), or larger-scale climate drivers, such as El Niño years in 1986-87, 1991-92, 1994-95 and 1997-98. However, another possibility is that, because all of the sites were identified during surveys in 1984, monitoring locations were biased towards sites that happened to be high-flowering in that year. These populations could have remained synchronous for many years due to remaining on their own endogenous cycles, even in the absence of shared environmental drivers.

\section{Analysis of subsequent patterns}

If among-population synchrony during the first 14 years of this study were due to correlated environmental drivers, then synchrony among sites should remain constant through time, possibly increasing after the winter of 1997-1998, which was one of the strongest El Niño events on record. Alternatively, if synchrony were due to within-population forces, such as pollen coupling, then within-population synchrony should remain constant through time (given minimal effects of water addition; see experiment \#1), but among-population synchrony should decay as uncorrelated stochastic events dominate over initial conditions.

I evaluated these two possibilities by calculating synchrony of flowering by individual plants at the original three sites, from 1986 to 2008. I coded individual plants in each year as flowering (1), nonflowering (0) or missing data (not alive or not surveyed in that year). Using these 0/1 time series, I calculated Pearson correlations between each pair of plants, then used the average correlation over all pairs of plants as a measure of synchrony. Note that correlations of binary data retain the properties of $r=1$ for matching time series, $r=-1$ for completely inverted time series, and $r=0$ for random sequences, even though the sampling distribution of $r$ is different than for normally distributed data.



Fig. 2 Changes in synchrony through time within and among three long-term monitoring sites: Haynes Creek, McDevitt Creek, and Sheep Corral Gulch. "Synchrony" is defined as the average pairwise Pearson correlation between time series of flowering by individual plants $(0=$ flowering, $1=$ not $)$. Graphs show point
Confidence limits for correlations were calculated by bootstrapping, i.e., resampling plants in the data set with replacement. I calculated correlations for all pairs of plants within each site, and between all plant pairs in each pair of sites. To evaluate patterns through time, synchrony was calculated for 10 -year moving windows, and differences in synchrony were inferred from nonoverlapping $95 \%$ bootstrap limits.

\section{Results}

Flowering tended to become more synchronous through time within sites (Fig. 2a). This pattern was driven by a strong increase at one site, Haynes Creek (top line in Fig. 2a), and more modest increases at McDevitt Creek and Sheep Corral Gulch. Even in these two sites, flowering was more synchronous during the last decade of the study than during the first decade $(95 \%$ limits of early and late decades at each site: Haynes, 1986-95: 0.256-0.392, 1997-2008: 0.618-0.828; McDevitt, 1986-95: 0.2250.478, 1997-2008: 0.314-0.450; Sheep, 1986-95: 0.3520.469, 1997-2008: 0.434-0.547). Flowering tended to become less synchronous through time among sites (Fig. 2b). This pattern was driven by decreases in the synchrony among plants at Sheep Corral Gulch and each of the two Idaho sites, and a modest increase in synchrony among plants in the two Idaho sites (Fig. 2b; $95 \%$ limits of early and late decades for each site pair: HaynesMcDevitt, 1986-95: 0.155-0.308, 1997-2008: 0.3180.529; Haynes-Sheep, 1986-95: 0.257-0.366, 1997-2008: -0.010-0.199; McDevitt-Sheep, 1986-95: 0.249-0.394, 1997-2008: -0.286 to -0.157$)$.

\section{Experiment \#1: water addition}

\section{Past research}

To test whether early spring precipitation induced flowering and synchrony, we watered plots at McDevitt

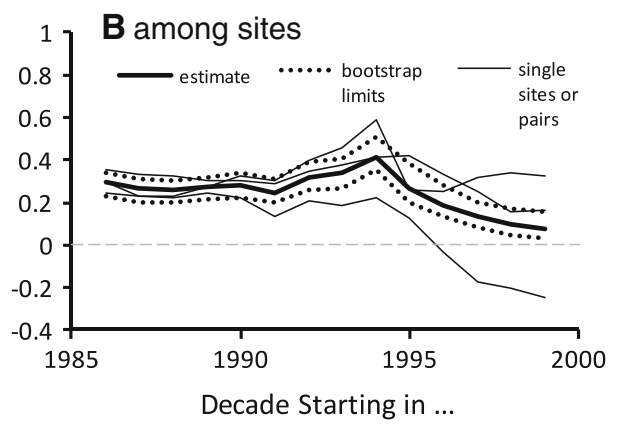

estimates (thick lines), $95 \%$ bootstrap confidence limits, calculated by bootstrapping individual plants with replacement within sites (thick dashed lines), and point estimates for each pair of sites (thin lines) 
Creek and Sheep Corral Gulch (Crone and Lesica 2006). Plots were watered in late March or early April during the first weekends after March 1 when the ground was not frozen. We watered until plots reached field capacity over $2 \mathrm{~h}, 16 \mathrm{l} / \mathrm{m}^{2}(3.2 \mathrm{~cm}$ rainfall events) at McDevitt Creek, and $12 \mathrm{l} / \mathrm{m}^{2}$ (2.4 cm rainfall events) at Sheep Corral Gulch, increasing precipitation by $\sim 20 \%$ of the average annual total and $\sim 100 \%$ of the average monthly total for March and April. 1- $\mathrm{m}^{2}$ quadrats within transects were divided into three treatment groups: one-time watering ("pulse" watering) in 2000 , water addition for 3 years (2000-2002, "press" watering), and unwatered controls. Plots included in the experiment were separated by $1-\mathrm{m}^{2}$ unmanipulated buffers (the remaining plots). This design enabled us to use a powerful before-after control-impact analysis to evaluate effects of supplemental water.

If water caused synchrony, we expected high flowering in watered plots, even though these were lowflowering years in other plots. However, although March precipitation was the best environmental correlate of flowering from 1986 to 1999, water addition had no detectable effect on flowering probability, reproductive effort (inflorescences per flowering plant), or seed set (Crone and Lesica 2006). Our published analysis included only control and press-watered plots, but there were also no detectable effects of pulse watering during the first 3 years (Crone, unpublished analyses).

\section{Analysis of subsequent patterns}

One critique of our previous analyses is that watering may have increased flowering in subsequent years, even if it did not immediately cause high flowering in watered plots. Here, I analyze patterns of flowering through 2008 , to test whether water addition had any detectable long-term effects. For these analyses, I divided plots into three temporal periods: before watering (1986-1999), during watering (2000 in pulse-watered plots, 2000-2002 in press-watered plots), and after watering (2001-2008 in pulse-watered plots, 2003-2008 in press-watered plots). I tested whether flowering in press- and pulse-watered plots differed from control plots during and after watering using generalized linear mixed models with temporal period as a fixed factor and year and plant ID as random factors. Data were analyzed as records of flowering by individual plants (binomial error, logit link function). Analyses were implemented using the lmer function in R (Bates and Maechler 2010; R Development Core Team 2010), and the two treatment groups were matched to appropriate temporal periods in the controls by running the analyses twice with different years identified as "during" versus "after" in control plots, and selecting the appropriate test period for each treatment period. Following this overall comparison of temporal periods, I used post hoc contrasts of individual years to interpret results of the main analysis. These contrasts were calculated by rerunning the mixed model with individual years from 2000 to 2008 as categorical fixed factors, rather than "during" and "after".

\section{Results}

Continued monitoring revealed some effects of watering treatments, but these were subtle, and not consistent with the hypothesis that early spring precipitation causes plants to flower. At McDevitt Creek, there was some tendency for higher flowering in press-watered plots. Although this effect was distinctly nonsignificant in the main analysis $(p>0.20$ for both treatments, during and after, Table 1), individual year contrasts showed somewhat higher flowering in press-watered plots in 2000 $(Z=1.7, p=0.089), 2002(Z=1.4, p=0.155), 2006$ $(Z=1.5, p=0.132)$ and $2007(Z=2.0, p=0.050)$, but lower flowering in pulse-watered plots in 2003 $(Z=-1.9, p=0.055) \quad$ (Fig. 3b). At Sheep Corral Gulch, press-watered plants were significantly less likely to flower after treatments ended (after $\times$ press effect, Table 1). This effect was due to lower probability of flowering during the extremely high-flowering year, 2005 $(Z=-2.4, p=0.015)$, and somewhat lower flowering in $2007(Z=-1.6, p=0.110)$ (see both effects in Fig. 3a). Although the "after $\times$ pulse" effect was not statistically significant, the overall pattern of flowering in pulse-watered plots echoed patterns in the presswatered plots (post hoc contrasts: 2005: $Z=-2.2$, $p=0.028$; 2007: $Z=-1.5, p=0.0129$; see Fig. 3b).

\section{Experiment \#2: flower removal}

\section{Past research}

In this experiment, we manipulated seed set to see if this would desynchronize flowering, as predicted by the pollen-coupling model. The rationale behind our predictions was twofold: first, if alternate-year flowering is due to resource depletion by individual plants, then preventing plants from setting seed in a high-flowering year should cause them to flower again the next year (unlike plants that were allowed to set seed). Second, if plants are pollen limited and therefore set fewer seeds in low-flowering years, these desynchronized plants should keep flowering until the next high-flowering year. We manipulated seed set by removing flowers at two sites, Sheep Corral Ridge (Crone et al. 2009) and Reservoir Creek (see further discussion of flower removal methods and validation by Crone et al. 2009). Similar to the water supplementation experiment, we used two manipulations, "pulse" removal, in which flowers were removed in only 1 year, 2005, and "press" removal, 2005-2007.

The year 2005 was an unusually high-flowering and seed-set year at Sheep Corral Gulch (Fig. 1) and Sheep Corral Ridge (Fig. 4). Flowering from 2006 to 2008 exactly matched our expectations based on the pollencoupling hypothesis (Crone et al. 2009): pulse-removal 
Table 1 Analysis of effects of flower removal and water addition on flowering probability

A. Water addition experiment $\mathrm{a}^{\mathrm{a}}$

\begin{tabular}{|c|c|c|c|c|c|c|c|c|}
\hline & \multicolumn{4}{|c|}{ Sheep Corral Gulch } & \multicolumn{4}{|c|}{ McDevitt Creek } \\
\hline & Estimate & Std. error & $Z$ value & $\operatorname{Pr}(>|z|)$ & Estimate & Std. error & $Z$ value & $\operatorname{Pr}(>|z|)$ \\
\hline Pulse (pre-treatment) & 0.60 & 0.31 & 1.94 & 0.0527 & 0.20 & 0.50 & 0.40 & 0.6931 \\
\hline During $\times$ pulse & 0.28 & 0.58 & 0.49 & 0.6260 & -13.62 & 665.65 & -0.02 & 0.9837 \\
\hline After $\times$ pulse & -0.40 & 0.38 & -1.05 & 0.2946 & -0.41 & 0.57 & -0.72 & 0.4710 \\
\hline Press (pre-treatment) & 0.18 & 0.32 & 0.57 & 0.5690 & 0.05 & 0.44 & 0.11 & 0.9120 \\
\hline During $\times$ press & -0.29 & 0.59 & -0.50 & 0.6166 & 0.78 & 0.61 & 1.27 & 0.2048 \\
\hline After $\times$ press & -0.88 & 0.42 & -2.08 & 0.0377 & 0.19 & 0.54 & 0.36 & 0.7166 \\
\hline Random effects: & Std. dev. & & & & Std. dev. & & & \\
\hline Plant ID & 1.24 & & & & 1.24 & & & \\
\hline Year & 1.88 & & & & 1.41 & & & \\
\hline
\end{tabular}

B. Flower removal experiment ${ }^{\text {b }}$

\begin{tabular}{|c|c|c|c|c|c|c|c|c|}
\hline & \multicolumn{4}{|c|}{ Sheep Corral Ridge } & \multicolumn{4}{|c|}{ Reservoir Creek } \\
\hline & Estimate & Std. error & $Z$ value & $\operatorname{Pr}(>|z|)$ & Estimate & Std. error & $Z$ value & $\operatorname{Pr}(>|z|)$ \\
\hline Pulse (during) & 2.73 & 0.83 & 3.30 & 0.0010 & 1.55 & 0.94 & 1.65 & 0.0999 \\
\hline After $\times$ pulse & -2.37 & 0.91 & -2.59 & 0.0096 & -1.74 & 0.94 & -1.86 & 0.0634 \\
\hline Press (during) & 1.31 & 0.45 & 2.93 & 0.0033 & 0.98 & 0.49 & 1.99 & 0.0466 \\
\hline After $\times$ press & -0.91 & 0.76 & -1.20 & 0.2312 & -0.07 & 0.59 & -0.12 & 0.9084 \\
\hline Random effects: & Std. dev. & & & & Std. dev. & & & \\
\hline Plant ID & 1.13 & & & & 1.26 & & & \\
\hline Year & 0.76 & & & & 0.41 & & & \\
\hline
\end{tabular}

"For the water addition experiment, "Press" and "Pulse" coefficients test the (uninteresting) difference during the pre-treatment years (1986-1999), interactions with "During" test the difference during watering, and interactions with "After" test the difference between treatment groups after watering

"For the flower removal experiment, "Press" and "Pulse" coefficients test whether treatment plants differ from controls during the experiment, and interactions with "After" indicate whether treatment effects ended when we expected plants to resynchronize
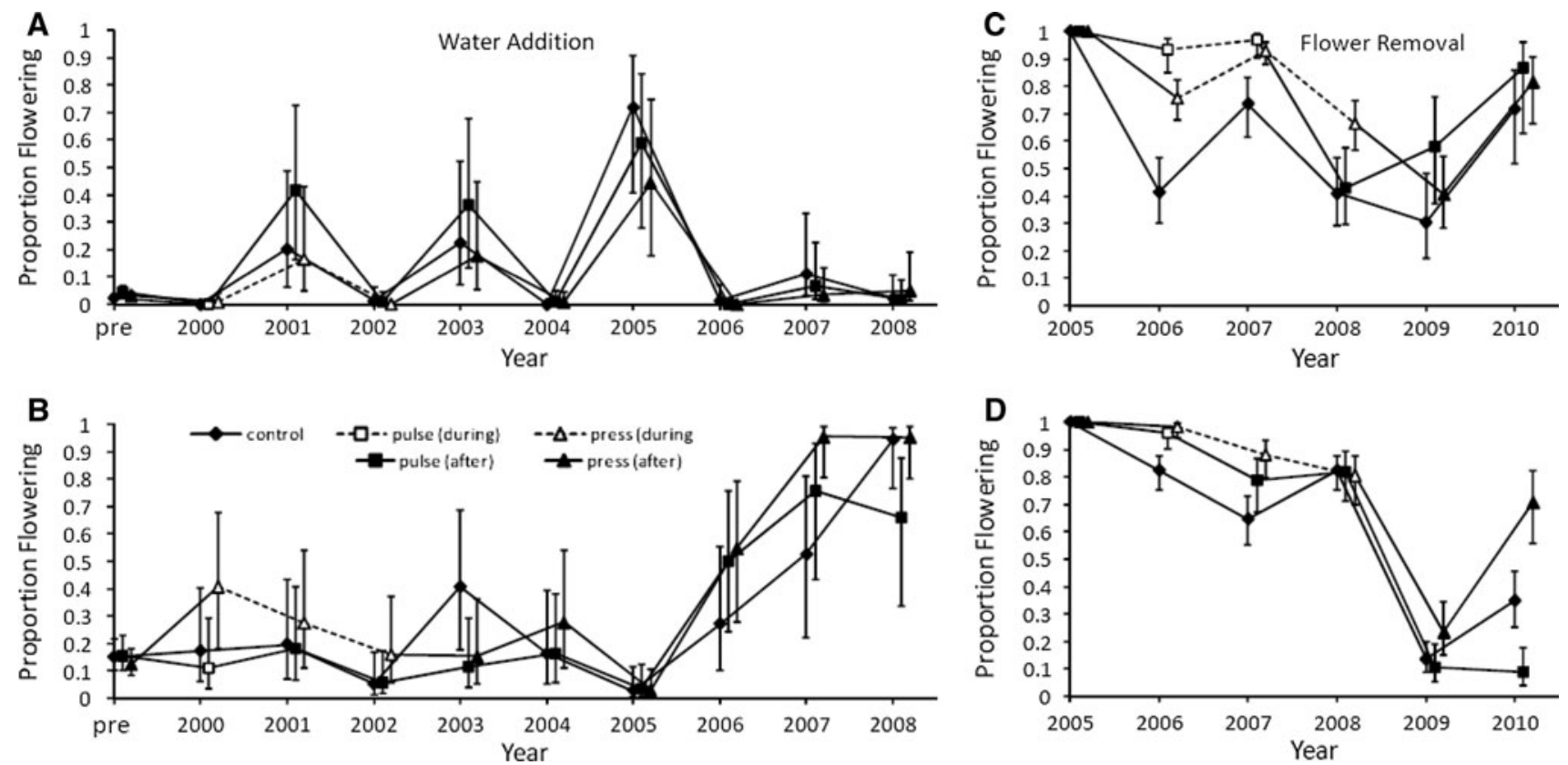

Fig. 3 Effects of flower removal and water addition on A. scaphoides flowering. Our a priori expectations were that both treatments would increase flowering in the "during" years (open circles, dashed lines), relative to control plots. See further explanation in text. a Water addition at Sheep Corral Gulch, b water addition at McDevitt Creek, $\mathbf{c}$ flower removal at Sheep Corral Ridge, $\mathbf{d}$ flower removal at Reservoir Creek; "pre" refers to pre-treatment (1986-1999) geometric means in the watering experiment. Bars show \pm 1 standard error 


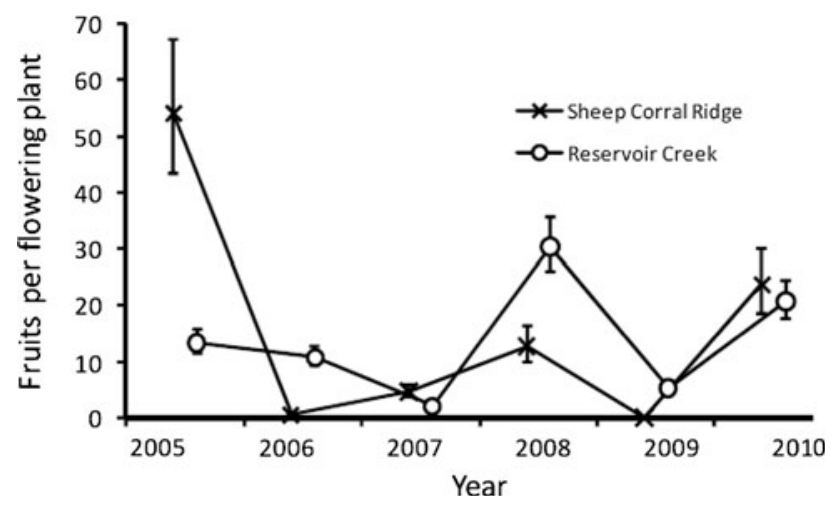

Fig. 4 Fruit set per flowering plant (control plants only) during and after the flower removal experiment. Bars show \pm 1 standard error

plants were more likely than control plants to flower in 2006 (Fig. 3c). These plants were allowed to set seed in 2006 , but seed set was low, presumably due to densitydependent pollen limitation. They were more likely than control plants to flower in 2007. The year 2007 was a relatively high-flowering year, in which plants set seed. Pulse-removal plants were not more likely than controls to flower in 2008. Press-removal plants, which were not allowed to set seed from 2005 to 2007, were more likely than control plants to flower throughout the experiment (2006-2008).

The year 2005 was a high-flowering year at Reservoir Creek (Fig. 1), but not one with unusually high seed set (Fig. 4). We have not previously published the results of the manipulation at Reservoir Creek, although we continued to monitor plants at both sites through 2010 .

\section{Analysis of subsequent patterns}

The pollen-coupling model makes specific predictions about the performance of plants in each site and treatment through time. At Sheep Corral Ridge, 2008 was also a year with relatively high seed set (Fig. 4). Therefore, both press and pulse plants should have resynchronized with control plants after this year (i.e., in 2009 and 2010). At Reservoir Creek, 2006 was a relatively high-flowering and high-seed year, so pulse-removal plants should have resynchronized with control plants starting in 2007. Press-removal plants should have continued to have higher flowering probability than controls through 2008. Since 2008 was a high-flowering year, press-removal plants should have resynchronized with control plants in 2009 and 2010.

We tested these hypotheses using generalized linear models. This analysis broadly followed the methods used for the watering experiment (fixed factors of time period and treatment, random effects of individual plant and year, binomial error, logit link, etc.), with two exceptions: First, we defined treatment periods based on years when we a priori expected higher seed set, not based on years when treatments were applied. For pulse-removal plants
Table 2 Sample size of surviving plants in the flower removal experiment

\begin{tabular}{llllllll}
\hline \multirow{2}{*}{ Year } & \multicolumn{2}{l}{ Sheep Corral Ridge } & & \multicolumn{3}{l}{ Reservoir Creek } \\
& Control & Pulse & Press & & Control & Pulse & Press \\
\hline 2006 & 25 & 19 & 47 & & 48 & 25 & 28 \\
2007 & 23 & 19 & 44 & & 48 & 25 & 28 \\
2008 & 22 & 18 & 39 & & 48 & 24 & 27 \\
2009 & 11 & 8 & 20 & & 47 & 23 & 27 \\
2010 & 9 & 4 & 12 & & 35 & 21 & 16
\end{tabular}

Survival reflects a combination of natural mortality and harvest for resource allocation studies

at Sheep Corral Ridge, "during" was 2006-2007, and "after" was 2008-2010. For pulse-removal plants at Reservoir Creek, "during" was 2006 and "after" was 2007-2010. For press-removal plants at both sites, "during" was 2006-2008 and "after" was 2009-2010. Second, this experiment lacked a "before" period (though we controlled for past history by including only large flowering plants in the experiment, see Crone et al. 2009). Therefore, we set the "during" period as the reference period, which means that main effects of "pulse" and "press" treatments test whether these groups differed from control plants during years when we expected increased flowering, and interactions of treatments with "after" test whether these effects changed during the period when we did not expect increased flowering.

Control plants at Sheep Corral Ridge experienced higher than average mortality in 2006, presumably due to high costs of reproduction. We also harvested a subset of plants for resource allocation studies in 2008 (Crone and Sala, unpublished data). Therefore, the sample size and associated statistical power tended to decline through time (Table 2).

\section{Results}

At Sheep Corral Ridge, both treatments had significant positive effects on flowering during years when we expected low flowering (main effects, Table 1B; these are the same results and conclusions reported by Crone et al. 2009, albeit with a subtly different analysis). The after $\times$ pulse interaction was statistically significant, negative, and of similar magnitude to the main effect (Table 1B), which means that flowering by pulseremoval plants re-synchronized as expected (see Fig. 3c). The after $\times$ press interaction was not statistically significant ( $p=0.23$; Table 1B). However, the coefficient was negative and of similar magnitude to the main effect, largely supporting our expectation that press-removal plants did not continue to have higher flowering than control plants after they set seed in 2008 .

At Reservoir Creek, press-removal plants were significantly more likely ( $p=0.046$; Table $1 \mathrm{~B}$ ), and pulseremoval plants were marginally significantly more likely $(p=0.099$; Table 1B) to flower in years when we 
expected higher flowering. This effect disappeared as expected in pulse-removal plants (significant after $\times$ pulse interaction, Table 1B), though there was a tendency for lower flowering by pulse plants in 2010 (post hoc test for 2010: $Z=-1.86, p=0.0623$ ). However, press-removal plants continued to have significantly higher flowering in 2009 and 2010, in spite of relatively high-flowering plant densities and high-seed set in 2008 (highly nonsignificant after $\times$ press effect, Table $1 \mathrm{~B}$; post hoc year contrasts: $Z=0.95, p=0.343$ in 2009; $Z=1.89, p=0.058$ in 2010).

At both sites, seed set in 2007 was lower than I expected, relative to flowering plant density (see Figs. 1, 4).

\section{Discussion}

As with many other ecological processes (see, e.g., review by Bjørnstad and Grenfell 2001), our research with $A$. scaphoides broadly confirms the idea that both endogenous and exogenous factors affect flowering in this species. However, the endogenous processes, resource allocation and density-dependent pollen limitation, have clear and predictive synchronizing effects. In contrast, exogenous processes such as temperature and precipitation seem to be broadly associated with long-term resource gain and flowering dynamics (see also Crone et al. 2005), but do not act as synchronizing cues, in the sense of directly causing plants to flower. As in any study, it could be that we have overlooked some key combination of weather variables that directly synchronize reproduction. For example, Piovesan and Adams (2001) found higher flowering by European beech in years with early summer droughts, following years with cool, moist summers. The variable we manipulated, precipitation just before emergence, was the strongest correlate of high-flowering years, but flowering was also marginally significantly associated with low precipitation in the preceding September, which might be the time at which developmental decisions for the following year are made. Puzzlingly, flowering in May-July of year $t$ was also correlated with June precipitation in that same year (see Crone and Lesica 2006). Still, searching for environmental drivers of synchrony may be an unnecessary and futile exercise, since pollen coupling is sufficient to explain alternateyear flowering in this system.

Following up on our previous studies generally corroborated our past conclusions, but also revealed three surprising results, only one of which is straightforward to explain. First, seed set in 2007 was noticeably lower than expected in relation to plant density. We (Crone et al. 2009) speculated that this might have been due to persistent costs of high reproduction at Sheep Corral Ridge in 2005. However, the effect is even stronger at Reservoir Creek, where seed set was not especially high in 2005. An alternative explanation is that 2007 was one of the hottest and driest summers on record in our study area (see further discussion by
Gremer 2010). This explanation would be consistent with time series analysis using mechanistic pollen-coupling models (Crone et al. 2005), in which precipitation explained $\sim 20 \%$ of the total variance in seed set, even though environmental drivers were neither necessary nor sufficient to explain alternate-year flowering.

More puzzlingly, press-removal plants at Reservoir Creek did not synchronize with the rest of the population after the high-flowering and high-seed year in 2008 . Instead, press-removal plants continued to have a higher flowering probability through 2010 at this site. This was the only case in which flowering dynamics differed significantly from our expectations based on the pollencoupling model. A partial explanation for this phenomenon is that, although press-removal and control plants had nearly identical seed set in 2008, press-removal plants tended to have lower seed set in 2009 and 2010 (mean \pm standard errors of ln-transformed seed pods per plant, 2008: control $3.41 \pm 0.16$, press $3.42 \pm$ 0.22 ; 2009: control $1.67 \pm 0.19$, press $1.37 \pm 0.28$; 2010: control $3.03 \pm 0.17$, press $2.41 \pm 0.24$ ). Therefore, higher flowering in 2010 could be associated with lower seed set in 2009, though the cause of this lower seed set is unknown. We have only monitored flowering for 8 years at Reservoir Creek, but, so far, flowering has been less synchronous and less distinctly bimodal at this site than at Sheep Corral Gulch (see Fig. 1). Therefore, in retrospect, it may not be surprising that pollen coupling is weaker at this site, since flowering is also less synchronous.

Finally, although precipitation was correlated with higher flowering in our time series analysis, supplemental watering from 2000 to 2002 significantly reduced the number of flowering plants in 2005, the unusually highflowering year. One explanation for this pattern would be that watering increased the intensity of competition. However, supplemental water did not increase total plant cover of all species, a loose measure of the strength of competition, and cover remained very low $(<33 \%)$ throughout the study (Crone and Lesica 2006). A second possible explanation is that resource depletion leads to mathematically chaotic flowering by $A$. scaphoides plants (see mathematical analysis by Crone et al. 2005). One of the defining features of mathematical chaos is that small changes in dynamical parameters can lead to long-term differences in system dynamics (see, e.g., Hastings et al. 1993). I explored this possibility numerically, using pollen-coupling models fit to $A$. scaphoides. In many cases, a short-term resource pulse led to reduced flowering in future years. However, this effect was usually accompanied by increased reproduction during the resource pulse, which we did not see in our experiments. An alternative explanation is that resource allocation by plants is phenotypically plastic, and changes in relation to resource availability. Plants could plausibly respond to higher resource availability by allocating more resources to growth and less to reproduction, moving away from a ruderal strategy (sensu Grime 1979) in response to increased water. For 
example, Mimulus guttatis, a facultative annual plant, tends to delay flowering in more productive sites (Galloway 1995; Hall and Willis 2006).

Because experiments are not feasible in many systems, most studies infer mechanisms of synchrony from correlations of seed production with potential drivers (see, e.g., review by Kelly and Sork 2002, and meta-analysis by Schauber et al. 2002). Koenig and Knops (1998) hypothesized that environmental factors synchronized seed production in conifers because seed production was synchronous at continental scales, similar to the scales of synchrony in climate variables (Koenig 2002), but not to the scale of pollen movement (Liebhold et al. 2004b). Our experiments throw a cautionary light on these correlational studies. Analyses of our first 14 years of monitoring suggested that spring precipitation and/or El Niño events were likely synchronizing forces. However, reproduction became less synchronous after the strong 1997-98 El Niño year, and water addition just prior to emergence did not cause plants to flower that year. Although many correlational studies must surely reveal causal factors, a few other studies have shown that correlations between weather variables and mast seeding shift in space and time. For example, Brockie (1986) reported that flowering by Phormium spp., a genera of herbaceous monocots, was correlated with prior autumn temperatures based on a 10-year time series, but this correlation disappeared when patterns at the same sites were reanalyzed over 18 years (Schauber et al. 2002). Similarly, environmental variables that correlated with mast seeding by dipterocarps in Malaysia were not associated with mast events in the Philippines (Hamann 2004). Finally, Kelly et al. (2008) found that temperature in the previous year's growing season was correlated with flowering by a perennial tussock grass, but experimental manipulations of temperature tended to increase flowering in the year of warming, not the following year. These few examples, and our own experience, do not mean that exogenous factors rarely synchronize mast seeding. However, they imply that endogenous processes, such as pollen coupling, may be more important than has previously been assumed.

Acknowledgments I am grateful to A. Sala, J. Gremer and (especially) P. Lesica for years of productive collaboration, and to A. Satake for encouraging me to prepare this article. This article was written while E. Crone was supported by the National Science Foundation, NSF DEB 10-20889 and NSF DEB 05-15756 (to E. Crone and A. Sala). Our past research in this system has been supported by grants from the US Bureau of Land Management (to P. Lesica), the National Sciences and Engineering Research Council of Canada, and NSF DEB 02-40963 and DEB 02-36427.

\section{References}

Abrahamson A, Layne JN (2003) Long-term patterns of acorn production for five oak species in xeric Florida uplands. Ecology 84:2476-2492
Ashton PS, Givnish TJ, Appanah S (1988) Staggered flowering in the Dipterocarpaceae: new insights into floral induction and the evolution of mast fruiting in the aseasonal tropics. Am Nat 132:44-66

Barneby RC (1964) Atlas of North American astragalus. New York Botanical Garden, Bronx

Bates D, Maechler M (2010) lme4: linear mixed-effects models using S4 classes. R package version 0.999375-36. http://CRAN. R-project.org/package $=$ lme 4

Bjørnstad ON (2000) Cycles and synchrony: two historical 'experiments' and one experience. J Anim Ecol 69:869-873

Bjørnstad ON, Grenfell BT (2001) Noisy clockwork: time series analysis of population fluctuations in animals. Science 293: 638-643

Brockie RE (1986) Periodic heavy flowering of New Zealand flax (Phormium, Agavaceae). NZ J Bot 24:381-386

Crone EE, Lesica P (2004) Causes of synchronous flowering in Astragalus scaphoides, an iteroparous perennial plant. Ecology 85:1944-1954

Crone EE, Lesica P (2006) Pollen and water limitation in Astragalus scaphoides, a plant that flowers in alternate years. Oecologia 150:40-49

Crone EE, Polansky L, Lesica P (2005) Empirical models of pollen limitation, resource acquisition, and mast seeding by a bee-pollinated wildflower. Am Nat 166:396-408

Crone EE, Miller E, Sala A (2009) How do plants know when other plants are flowering? Resource depletion, pollen limitation and mast-seeding in a perennial wildflower. Ecol Lett 12:1119-1126

Ehrlèn J, Lehtilä K (2002) How perennial are perennial plants? Oikos 98:308-322

Galloway LF (1995) Response to natural environmental heterogeneity: maternal effects and selection on life-history characters and plasticities in Mimulus guttatus. Evolution 49:1095-1107

Geer SM, Tepedino VJ, Griswold TL, Bowlin WR (1995) Pollinator sharing by three sympatric milkvetches, including the endangered species Astragalus montii. Great Basin Nat 55: $19-28$

Gremer J (2010) Causes and consequences of prolonged dormancy: why stay belowground? Ph.D. dissertation. University of Montana, Montana

Hall MC, Willis JH (2006) Divergent selection on flowering time contributes to local adaptation in Mimulus guttatus populations. Evolution 60:2466-2477

Hamann A (2004) Flowering and fruiting phenology of a Philippine submontane rain forest: climatic factors as proximate and ultimate causes. J Ecol 92:24-31

Hastings A, Hom CL, Ellner S, Turchin P, Godfray HCJ (1993) Chaos in ecology: is mother nature a strange attractor? Annu Rev Ecol Syst 24:1-33

Isagi Y, Sugimura K, Sumida A, Ito H (1997) How does masting happen and synchronize? J Theor Biol 187:231-239

Janzen DH (1976) Why bamboos wait so long to flower. Annu Rev Ecol Syst 7:347-391

Karron JD (1987) The pollination ecology of co-occurring geographically restricted and widespread species of Astragalus (Fabaceae). Biol Conserv 39:179-193

Kelly D, Sork VL (2002) Mast seeding in perennial plants: why, how, where? Annu Rev Ecol Syst 33:427-447

Kelly D, Turnbull M, Pharis R, Sarfati M (2008) Mast seeding, predator satiation, and temperature cues in Chionochloa (Poaceae). Popul Ecol 50:343-355

Koenig WD (2002) Global patterns of environmental synchrony and the Moran effect. Ecography 25:283-288

Koenig WD, Knops JMH (1998) Scale of mast-seeding and treering growth. Nature 396:225-226

Lesica P (1987) A technique for monitoring nonrhizomatous perennial plant species in permanent belt transects. Natural Areas Journal 7:65-68

Lesica P (1995) Demography of Astragalus scaphoides and effects of herbivory on population growth. Great Basin Nat 55: $142-150$ 
Liebhold A, Koenig WD, Bjørnstad ON (2004a) Spatial synchrony in population dynamics. Annu Rev Ecol Evol Syst 35:467-490

Liebhold A, Sork V, Peltonen M, Koenig W, Bjørnstad ON, Westfall R, Elkinton J, Knops JMH (2004b) Within-population spatial synchrony in mast seeding of North American oaks. Oikos 104:156-164

Lyles D, Rosenstock TS, Hastings A, Brown PH (2009) The role of large environmental noise in masting: general model and example from pistachio trees. J Theor Biol 259:701-713

McKone MJ, Kelly D, Lee WG (1998) Effect of climate change on mast-seeding species: frequency of mass flowering and escape from specialist insect seed predators. Glob Change Biol 4: $591-596$

Norton DA, Kelly D (1988) Mast seeding over 33 years by Dacrydium cupressinum Lamb. (rimu) (Podocarpaceae) in New Zealand: the importance of economies of scale. Funct Ecol 2: 399-408

Ostfeld RS, Keesing F (2000) Pulsed resources and community dynamics of consumers in terrestrial ecosystems. Trends Ecol Evol 15:232-237
Piovesan G, Adams JM (2001) Masting behaviour in beech: linking reproduction and climatic variation. Can J Bot 79:1039-1047

R Development Core Team (2010) R: a language and environment for statistical computing. R Foundation for Statistical Computing, Vienna, Austria. ISBN 3-900051-07-0, URL: http:// www.R-project.org/

Satake A, Iwasa Y (2000) Pollen coupling of forest trees: forming synchronized and periodic reproduction out of chaos. J Theor Biol 203:63-84

Satake A, Iwasa Y (2002) The synchronized and intermittent reproduction of forest trees is mediated by the Moran Effect, only in association with pollen coupling. J Ecol 90:830-838

Schauber EM, Kelly D, Turchin P, Simon C, Lee WG, Allen RB, Payton IJ, Wilson PR, Cowan PE, Brockie RE (2002) Masting by eighteen New Zealand plant species: the role of temperature as a synchronizing cue. Ecology 83:1214-1225 